\title{
A Brief Review of Responsible AI and Socially Responsible Investment in Financial and Stock Trading
}

\author{
A. K. M. Amanat Ullah \\ Department of Computer Science and \\ Engineering \\ Ahsanullah University of Science and \\ Technology \\ Dhaka, Bangladesh \\ amanat.ndc@gmail.com
}

Md. Muzahidul Islam Rahi

Department of Computer Science and Engineering

BRAC University

66 Mohakhali, Dhaka-1212, Bangladesh md.muzahidul.islam.rahi@g.bracu.ac.bd

\author{
Samiha Sultana \\ Department of Computer Science and \\ Engineering \\ BRAC University \\ 66 Mohakhali, Dhaka-1212, Bangladesh \\ samiha.sultana@g.bracu.ac.bd
}

\author{
Md. Ashraful Alam \\ Department of Computer Science and \\ Engineering \\ BRAC University
}

66 Mohakhali, Dhaka-1212, Bangladesh

ashraful.alam@bracu.ac.bd

\author{
Fahim Faisal \\ Department of Computer Science and \\ Engineering \\ BRAC University \\ 66 Mohakhali, Dhaka-1212, Bangladesh \\ fahimemcee@gmail.com
}

\author{
Md. Golam Rabiul Alam \\ Department of Computer Science and \\ Engineering \\ BRAC University \\ 66 Mohakhali, Dhaka-1212, Bangladesh \\ rabiul.alam@bracu.ac.bd
}

\begin{abstract}
Automated trading is used in most of the major markets of our world. In order to ensure sustainable development, incorporating ethical and socially responsible ideas while designing these Artificial Intelligence (AI) systems has become a necessity. Both the industry and the academia are working towards Responsible AI, which can make Socially Responsible Investments (SRI). This paper reviews the research on SRI investment in the financial sector and evaluates these methods, which can help find future research directions in Computational Finance. This survey looks at the machine learning techniques used for ethical decision-making while stock or forex trading, which will benefit any further research work on Responsible AI in Finance.
\end{abstract}

Index Terms-Responsible AI, Socially Responsible Investment (SRI) , Stock Market Trading, Computational Finance

\section{INTRODUCTION}

In several exchanges across the globe, automated trading and high-frequency trading (HFT) has become the norm. HFT entails using automated algorithms to perform proprietary trading techniques. HFTs compete for making profits consistently on each trade by swiftly buying and selling positions many times a day without long-term investment [1]. While figures fluctuate due to the difficulties of determining HFT is responsible for a particular trade, current estimates show that HFT accounts for about 60 percent of equities trades in the United States, and for Canada and London the figure is respectively $40 \%$ and $35 \%$ [2], [3]. As artificially intelligent systems have such a massive share in the market, only aiming for profit can lead to the fall of a particular industry, community, or country. If properly managed, these systems can help the economy bloom in all sectors on the flip side. Therefore, It is of utmost importance that investors who harness the power of Artificial Intelligence follow specific guidelines that make them socially responsible and considerate towards Environmental, Social, and Governance metrics.

The IEEE P7000 standards initiatives were established in 2019 to address ethical concerns in designing autonomous and intelligent systems. This decision was made in the wake of increasing public concern about the unintended effects of artificial intelligence (AI), exacerbated by the absence of a proactive procedure for addressing ethical issues in professional practice. The difficulty in transitioning from principles to practice, on the other hand, poses a major obstacle to the application of ethical standards [4].

According to Scopino, if a human builds an AI trader without intending to conduct market manipulation and the AI system performs market manipulation with discretion, the person may not be held liable under the current US regulatory framework. [5]. Therefore, the need for evaluating AI trading systems has become essential. Investors and academic scholars are now trying to find ways to include ethical decision-making capabilities of algorithmic trading systems.

Investors have traditionally concentrated on investment returns by carefully reviewing financial data to identify the bestperforming companies. Investors are growing more interested in other elements of businesses than simply profits because of a recent shift in attitudes about sensitive issues such as global warming and migrants [6]. 


\section{ImPACTS OF AUTOMATED TRADING}

Technical innovation has always resulted in more growth and a better average quality of life in the past; however, this does not imply that new technology adoption has always been without resistance [7]. As the Luddite rebellion in the 18th century demonstrated, technological development and the consequent displacement or change in the status of the economy has generated considerable societal dissatisfaction in the past, as beautifully shown in Charlie Chaplin's renowned film "Modern Times." [8]. The present wave of AI research has already generated significant public discussion regarding its economic and living-condition consequences. A growing number of individuals and groups are warning about the potential detrimental impact of AI deployment on the financial sector. Some predict that AI will have even more drastic consequences than past technology revolutions [9].

HFT activity has increased dramatically in recent years, prompting both academics and authorities to wonder if it is helpful to financial markets. Although the results are often ambiguous, recent academic research examined the impact of high-frequency trading (HFT) on different market quality indicators such as liquidity, transaction costs, market integrity, and efficiency [10].

\section{A. Stock Volatility}

Automated trading is positively associated with stock price volatility [11]. The studies found that high-frequency trading has a detrimental impact on the market's capacity to integrate basic information about firms into asset pricing. When highfrequency trading is active, stock prices tend to overreact to fundamental news. Overall, high-frequency trading may have some negative consequences for the US capital market.

\section{B. Ripple Effect}

A key problem with HFT is that the combination of many distinct high-speed traders may put extra risk on the market and create excessive volatility. What if the different computer programs "misfire" in some way? Other investors may be seriously harmed as a result of this. The so-called "flash crash" of May 6, 2010, exemplifies our automated markets' potential to go haywire [12]. HFT may cause flash crashes, as occurred in 2010 on the BSE when volumes spiked unexpectedly owing to a glitch in a Delhi stock broker's trading algorithm, which resulted in buy and sell orders being executed repeatedly [13]. A flaw in a trading algorithm may have a cascading effect, triggering other trading algorithms and creating a hysterical run on stock prices causing a ripple effect in all related financial markets.

\section{Manipulative Strategies}

A variety of manipulative trading techniques try to shift prices away from their true value in order to benefit from the artificial difference [12]. Spoofing, Wash Sales, Quote Stuffing, Front running, and other order Triggering Strategies can be easily used to make a profit in an illegal manner using the power of Artificial Intelligence in Trading.

\section{RESPONSIBLE AI}

Because specific machine learning algorithms are opaque, there is a significant risk of unexpected outcomes, which may have real-world implications for humans and animals. Understanding how neural networks handle a particular input, even intuitively, may be difficult at the moment. This has many consequences in the Financial sector that are not yet completely understood. To begin with, determining an algorithm's implicit assumptions (for example, how much of the contextual background information it uses when making a decision) and, therefore, the possible dangers of utilizing it for this purpose may be challenging. Second, when an algorithm is expected to make predictions outside the boundaries of the training data, it may not be very clear. Making ensuring algorithms fail gracefully is, in fact, a significant research challenge [14]. Finally, an algorithm may be difficult to decipher as to why it made a certain choice. While these factors are wellacknowledged in the AI field, they have been largely ignored in recent debates about the technology's potential environmental advantages [15].

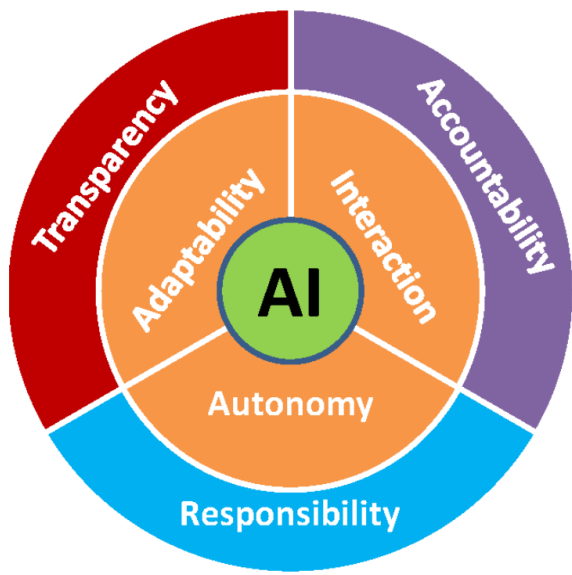

Fig. 1. ART principles for Responsible AI [9]

A growing understanding is that a responsible approach to $\mathrm{AI}$ is required to guarantee that $\mathrm{AI}$ technologies are used safely, sound, and equitably. This involves the need to think about the ethical consequences of machine choices and define AI's legal position. Concrete methods to the responsible design of AI, on the other hand, are almost non-existent. AI applications such as self-driving cars, companions, healthcare robots, rating and profile algorithms, which are now impacting society or will be in a few years, need responsive design, development, and usage of AI systems. In all of these cases, AI thinking should evaluate societal values, moral and ethical concerns, assess the relative importance of values held by stakeholders in various multicultural settings, explain its reasoning, and ensure transparency [9].

Autonomy, interactivity, and adaptability are common characteristics of AI systems. We suggest that these characteristics 
be supplemented with the principles of accountability, responsibility, and transparency (ART) [9], as shown in figure 1, to reflect society's concerns about AI ethics and guarantee that AI systems are created responsibly, integrating social and ethical norms.

\section{Work DONE ON SOCIALly Responsible AI}

Financial portfolio optimization has received a lot of attention. Many methods to developing decision assistance systems for stock trading have been explored. This includes Mean-Variance (MV) [16], TOPSIS [17], Logistic Regression [18], Autoregressive Integrated Moving Average (ARIMA) [19],Support Vector Machine (SVM) [20]-[22], Decision Tree [23], Long Short-Term Memory (LSTM) [24], Recurrent Neural Network (RNN) and Neural Networks [25].

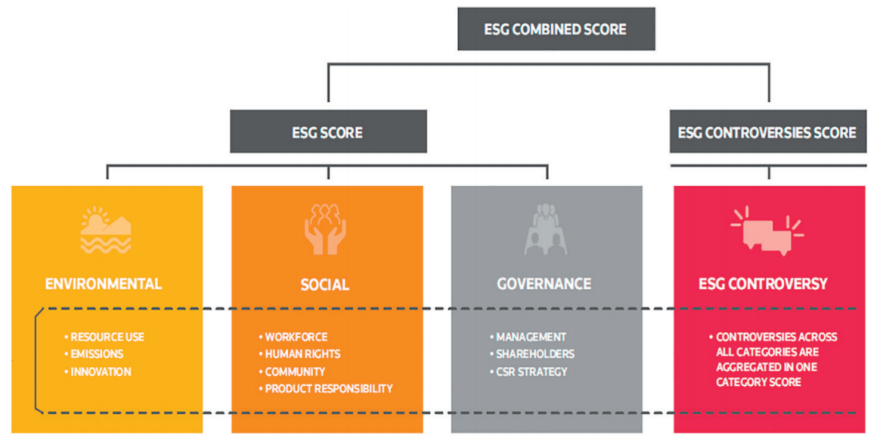

Fig. 2. ESG rating criteria [26]

However, limited study has been done on socially responsible investing and Responsible AI. However, the concept of socially responsible investing was first suggested in the 1980s [27], it has only recently become a hot issue in academia and business [28]. During this period, studies have linked ESG ratings to company financial success [29], [30] or socially responsible fund performance [31]-[33]. More study and implementation in this field have been facilitated by the availability of environmental, social, and governance (ESG) ratings in industry and also the academic sector [34].

One of the earliest studies that used SRI for financial trading was done by Galema et al. [35]. The study used FamaMacbeth, and Book-to-market regressions [35] to investigate the impact of SRI in returns of Financial assets. They aimed to clarify reasons behind the current gap between theoretical literature that suggests a link between SRI and stock returns and the majority of past research that finds no such link. The study [36], [37] uses machine learning to illustrate the impacts of automated trading in an artificially simulated agentbased stock market performed by Mizuta. There has been a recent trend in investing in companies that support CSR activities and have a high SRI score. Therefore advanced machine learning [38] techniques, namely Genetic Algorithm [37], Neural Networks [39], [40], and Decision Trees [41] used to evaluate Responsible AI and the impact of SRI metrics in the financial sector shown briefly in Table I.

\section{DISCUSSION}

The study by Mizuta focuses on whether an AI trader can learn to detect market manipulation even if the builder has no intention of manipulating the market [37]. This study is significant research in Responsible AI Domain. Though this was done with synthetic data, this research will pave the way towards further studies that can identify whether an AI trading bot is manipulating the market or not. [35] which was done in 2008. Vo et al. utilized Yahoo Finance to obtain both financial stock prices and public Environmental, Social Governance metrics ESG rating datasets. This is the first study that uses deep reinforcement [6] learning integrated with ESG ratings into a portfolio optimization model. The paper [38] there is a form of alpha in a company's ESG profile, but it can only be retrieved using sophisticated, non-linear methods like machine learning. The study [41] presents the ClimateQuant deep learning framework, which uses structured and unstructured climate data to predict the relationship between stock behavior and climate. The study provides a quantitative analysis to show that ClimateQuant's investing approach reduces carbon intensity while maintaining a good return on investment. In [41] unstructured data is gathered by parsing internet news feeds for climate-related incidents or accidents affecting the businesses in our universe. The climate data for structural data were obtained from the Climate Change Report (2014) [42]. This paper [39] offers a new method for addressing existing discrepancies in ESG ratings by using Machine Learning (ML) techniques to discover variables that contribute more to creating efficient portfolios. The research [40] examines a debate that focuses on policy implications for the three major ESG indicators that were shown to have the greatest impact on ROE and ROA: 1. Environmental innovation; 2. Employment productivity; and 3. Diversity and opportunity.

\section{CONCLUSIONS AND FUTURE WORK}

As SRI scores of the current year for a given company is not readily available or available in a vague way, some studies so far have used Artificial Intelligence to generate effective SRI scores. Some studies tried to show if the machine learning models are trying to manipulate the market and what sort of regulations be put in place so that Responsible use of AI is ensured. In contrast, other studies tried running various non-linear and deep learning methods on companies' limited available social and environmental scores to generate some form of alpha to gain an advantage over competitors while building a socially responsible portfolio.

To conclude, working with Responsible AI in the finance sector started to bloom in the year 2020. Therefore, there is much scope in this domain for research and improvement. Many studies could not generate a sizable return from investment as the SRI data available contains much noise and is unstructured. Steps to provide clean SRI data from data providers may mitigate this issue. Currently, the state-of-theart time series models work like a black box where the internal decision-making process is unknown to the end-user. As for responsible AI, new time series models with superior 
TABLE I

REVIEW OF RESPONSIBLE INVESTING IN THE FINANCIAL SECTOR USING AI \& MACHINE LEARNING

\begin{tabular}{|c|c|c|c|c|c|}
\hline Ref. & Author(s) & Year & Dataset & Decision Making & Major Contributions \\
\hline [38] & $\begin{array}{l}\text { De Franco, C., } \\
\text { et al. }\end{array}$ & 2020 & $\begin{array}{l}\text { Data Range: August } 2009 \text { to } \\
\text { March 2018. The capitalization- } \\
\text { weighted MSCI World Index } \\
\text { USD defines the investment } \\
\text { universe, which includes the } \\
\text { biggest capitalization listed } \\
\text { in the United States, Canada, } \\
\text { Western Europe, Japan, } \\
\text { Australia, New Zealand, Hong } \\
\text { Kong, and Singapore. }\end{array}$ & $\begin{array}{l}\text { Positive Machine } \\
\text { Learning Screening }\end{array}$ & $\begin{array}{l}\text { The Positive ML Screening beats all } \\
\text { other portfolios on an annualized basis, } \\
\text { outperforming the benchmark by } 2.76 \\
\text { percent, the ESG best-in-class portfolio } \\
\text { by } 2.94 \text { percent, and the Negative ML } \\
\text { Screening by } 4.77 \text { percent. While actual } \\
\text { yearly volatility stay between } 10.50 \text { per- } \\
\text { cent to } 11.14 \text { percent, the realized max- } \\
\text { imum drawdowns vary significantly: the } \\
\text { Negative ML Screening shows a }-22.47 \\
\text { percent loss from its peak, while the } \\
\text { Positive ML Screening shows a }-14.99 \\
\text { percent loss from its peak. }\end{array}$ \\
\hline [39] & Lanza, A., et al. & 2020 & $\begin{array}{l}\text { The study utilized the monthly } \\
\text { total return of each stock from } \\
\text { December 31, 2000 to April } \\
\text { 30, 2019. The dataset was used } \\
\text { from EURO STOXX } 300 \text {. }\end{array}$ & Decision Trees & $\begin{array}{l}\text { The model was used for trading for } \\
\text { one year. Using the ESG indicators, } \\
\text { the model had } 1.2 \% \text { return and had } \\
\text { a Sharpe ratio of } 0.5 \% \text { in the test } \\
\text { set. Using Environmental indicators, the } \\
\text { model had } 2.8 \% \text { return and } 1.8 \% \text { in the } \\
\text { out of sample data. }\end{array}$ \\
\hline$[40]$ & $\begin{array}{l}\text { De Lucia, C., et } \\
\text { al. }\end{array}$ & 2020 & $\begin{array}{l}\text { The study used a sample ver- } \\
\text { sion of the Thomson Reuters } \\
\text { ASSET4/EIKON database. A } \\
\text { maximum of } 5000 \text { observations } \\
\text { may be downloaded in the trial } \\
\text { edition. }\end{array}$ & $\begin{array}{l}\text { Random forest, Arti- } \\
\text { ficial Neural Network } \\
\text { (ANN), Support Vec- } \\
\text { tor Machine (SVM), k- } \\
\text { Nearest Neighbour, and } \\
\text { ridge regression }\end{array}$ & $\begin{array}{l}\text { The preliminary results indicated that } \\
\text { the majority of the algorithms could } \\
\text { accurately estimate Return of Equity } \\
\text { (ROE) and Return of Assets (ROA) } \\
\text { and that the projections outperformed } \\
\text { the baseline (the median value model). } \\
\text { Between the fourth and tenth deciles, } \\
\text { the authors discovered that sustainable } \\
\text { development policy, diversity and op- } \\
\text { portunity policy, and the wage gap all } \\
\text { had positive effects on ROE and ROA in } \\
\text { the range of }+10 \text { percent to } 16 \text { percent. }\end{array}$ \\
\hline
\end{tabular}


explainability can help make automated trading machines more ethical and safer for society and the environment.

\section{REFERENCES}

[1] M. Aitken, D. Cumming, and F. Zhan, "High frequency trading and end-of-day price dislocation," Journal of Banking \& Finance, vol. 59, pp. 330-349, 2015 10.1016/j.jbankfin.2015.06.011

[2] R. O'Reilly, "High frequency trading: Are our vital capital markets at risk from a rampant form of trading that ignored business fundamentals?" The Analyst, 2012.

[3] J. Grant, "High-frequency boom time hits slowdown," Financial Times, vol. 12,2011

[4] D. Peters, K. Vold, D. Robinson, and R. A. Calvo, "Responsible ai-two frameworks for ethical design practice," IEEE Transactions on Technology and Society, vol. 1, no. 1, pp. 34-47, 2020 10.1109/TTS.2020.2974991

[5] G. Scopino, "Do automated trading systems dream of manipulating the price of futures contracts-policing markets for improper trading practices by algorithmic robots," Fla. L. Rev., vol. 67, p. 221, 2015 [Online]. Available: https://scholarship.law.ufl.edu/flr/vol67/iss 1/5

[6] N. N. Vo, X. He, S. Liu, and G. Xu, "Deep learning for decision making and the optimization of socially responsible investments and portfolio," Decision Support Systems, vol. 124, p. 113097, 2019 10.1016/j.dss.2019.113097

[7] M. Marien, "The second machine age: Work, progress, and prosperity in a time of brilliant technologies," Cadmus, vol. 2, no. 2, p. 174, 2014. [Online]. Available: https://www.proquest.com/openview/ 6409179cf1cc0bfc0da426b324acb95a/1

[8] R. van Est, I. van Keulen, L. Kool, A. Van Waes, F. Brom, F. van der Zee, G. Gijsbers, J. Korsten, H. Lintsen, and J. Schot, Werken aan de robotsamenleving: Visies en inzichten uit de wetenschap over de relatie technologie en werkgelegenheid. Rathenau Instituut, 2015. [Online] Available: https://dspace.library.uu.nl/handle/1874/362889

[9] V. Dignum, "Responsible artificial intelligence: designing ai for human values," 2017. [Online]. Available: https://www.itu.int/en/journal/001/ Documents/itu2017-1.pdf

[10] V. Caivano, "The impact of high-frequency trading on volatility. evidence from the italian market," 2015 10.2139/ssrn.2573677

[11] F. Zhang, "High-frequency trading, stock volatility, and price discovery," Available at SSRN 1691679, 2010 10.2139/ssrn.1691679

[12] J. J. Angel and D. McCabe, "Fairness in financial markets: The case of high frequency trading," Journal of Business Ethics, vol. 112, no. 4, pp. 585-595, 2013 10.1007/s10551-012-1559-0

[13] V. Kutchu, "Growth and future of algorithmic trading in india," Gavesana Journal of Management, vol. 10, no. 2, pp. 83-93, 2018 [Online]. Available: https://vjim.edu.in/i/wp-content/uploads/2019/08/ Gavesana-July December 2018-issue2.pdf\#page $=88$

[14] D. Amodei, C. Olah, J. Steinhardt, P. Christiano, J. Schulman, and D. Mané, "Concrete problems in ai safety," arXiv preprint arXiv:1606.06565, 2016. [Online]. Available: https://arxiv.org/abs/1606. 06565

[15] O. R. Wearn, R. Freeman, and D. M. Jacoby, "Responsible ai for conservation," Nature Machine Intelligence, vol. 1, no. 2, pp. 72-73, 2019 10.1038/s42256-019-0022-7

[16] M. Rubinstein, "Markowitz's" portfolio selection": A fifty-year retrospective," The Journal of finance, vol. 57, no. 3, pp. 1041-1045, 2002 10.1111/j.1540-6261.1952.tb01525.x

[17] A. K. M. Amanat Ullah, M. T. Mahtab, and M. G. R. Alam, "Efficient portfolio management using topsis and ada-boost," in 2020 IEEE AsiaPacific Conference on Computer Science and Data Engineering (CSDE), 2020, pp. 1-6 10.1109/CSDE50874.2020.9411530

[18] A. Zheng and J. Jin, "Using ai to make predictions on stock market," Stanford University, Tech. Rep, Tech. Rep., 2017. [Online]. Available: http://cs229.stanford.edu/proj2017/final-reports/5212256.pdf

[19] J.-H. Wang and J.-Y. Leu, "Stock market trend prediction using arimabased neural networks," in Proceedings of International Conference on Neural Networks (ICNN'96), vol. 4. IEEE, 1996, pp. 2160-2165 10.1109/ICNN.1996.549236

[20] K.-j. Kim, "Financial time series forecasting using support vector machines," Neurocomputing, vol. 55, no. 1-2, pp. 307-319, 2003 10.1016/S0925-2312(03)00372-2
[21] S. Madge and S. Bhatt, "Predicting stock price direction using support vector machines," Independent work report spring, 2015. [Online]. Available: https://www.cs.princeton.edu/sites/default/ files/uploads/saahil_madge.pdf

[22] W. Huang, Y. Nakamori, and S.-Y. Wang, "Forecasting stock market movement direction with support vector machine," Computers \& operations research, vol. 32, no. 10, pp. 2513-2522, 2005 10.1016/j.cor.2004.03.016

[23] A. K. M. A. Ullah, F. Imtiaz, M. U. M. Ihsan, M. G. R. Alam, and M. Majumdar, "Combining machine learning classifiers for stock trading with effective feature extraction," 2021. [Online]. Available: https://arxiv.org/abs/2107.13148

[24] G. Chen, Y. Chen, and T. Fushimi, "Application of deep learning to algorithmic trading," Stanford University, Tech. Rep, Tech. Rep., 2017. [Online]. Available: http://cs229.stanford.edu/proj2017/ final-reports/5241098.pdf

[25] M. R. Hassan, B. Nath, and M. Kirley, "A fusion model of hmm, ann and ga for stock market forecasting," Expert systems with Applications, vol. 33, no. 1, pp. 171-180, 2007 10.1016/j.eswa.2006.04.007

[26] "Thomson reuters esg scores - date of issue: February 2019." [Online]. Available: https://www.readkong.com/page/ thomson-reuters-esg-scores-date-of-issue-february-2019-4522592

[27] H. Gray, New directions in the investment and control of pension funds. Investor Responsibility Research Center, 1983.

[28] N. Eccles and S. Viviers, "The origins and meanings of names describing investment practices that integrate a consideration of esg issues in the academic literature," Journal of business ethics, vol. 104, no. 3, pp. 389-402, 2011 10.1007/s10551-011-0917-7

[29] A. Fatemi, M. Glaum, and S. Kaiser, "Esg performance and firm value: The moderating role of disclosure," Global Finance Journal, vol. 38, pp. 45-64, 2018, special Issue on Corporate Social Responsibility and Ethics in Financial Markets. [Online]. Available: https://www.sciencedirect.com/science/article/pii/ S1044028316300680://doi.org/10.1016/j.gfj.2017.03.001

[30] G. Halbritter and G. Dorfleitner, "The wages of social responsibility - where are they? a critical review of esg investing," Review of Financial Economics, vol. 26, pp. 25-35, 2015. [Online]. Available: https://www.sciencedirect.com/science/article/pii/ S1058330015000233 ://doi.org/10.1016/j.rfe.2015.03.004

[31] B. R. Auer and F. Schuhmacher, "Do socially (ir)responsible investments pay? new evidence from international esg data," The Quarterly Review of Economics and Finance, vol. 59, pp. 51-62, 2016. [Online]. Available: https://www.sciencedirect.com/science/article/pii/ S1062976915000770 ://doi.org/10.1016/j.qref.2015.07.002

[32] F. Munoz, M. Vargas, and I. Marco, "Environmental mutual funds: Financial performance and managerial abilities," Journal of Business Ethics, vol. 124, no. 4, pp. 551-569, 2014 10.1007/s10551-013-1893-x

[33] A. Kempf and P. Osthoff, "The effect of socially responsible investing on portfolio performance," European Financial Management, vol. 13, no. 5, pp. 908-922, 2007 10.1111/j.1468-036X.2007.00402.X

[34] M. Von Wallis and C. Klein, "Ethical requirement and financial interest: a literature review on socially responsible investing," Business Research, vol. 8, no. 1, pp. 61-98, 2015 10.1007/s40685-014-0015-7

[35] R. Galema, A. Plantinga, and B. Scholtens, "The stocks at stake: Return and risk in socially responsible investment," Journal of Banking \& Finance, vol. 32, no. 12, pp. 2646-2654, 2008 10.1016/j.jbankfin.2008.06.002

[36] T. Mizuta, "An agent-based model for designing a financial market that works well," in 2020 IEEE Symposium Series on Computational Intelligence (SSCI). IEEE, 2020, pp. 400-406 10.1109/SSCI47803.2020.9308376

[37] T. Mizuta, "Can an ai perform market manipulation at its own discretion?-a genetic algorithm learns in an artificial market simulation," in 2020 IEEE Symposium Series on Computational Intelligence (SSCI). IEEE, 2020, pp. 407-412 10.1109/SSCI47803.2020.9308349

[38] C. De Franco, C. Geissler, V. Margot, and B. Monnier, "Esg investments: Filtering versus machine learning approaches," arXiv preprint arXiv:2002.07477, 2020. [Online]. Available: https://arxiv.org/ pdf/2002.07477.pdf

[39] A. Lanza, E. Bernardini, and I. Faiella, "Mind the gap! machine learning, esg metrics and sustainable investment," Machine Learning, ESG Metrics and Sustainable Investment (June 26, 2020). Bank of Italy Occasional Paper, no. 561, 2020 10.2139/ssrn.3659584 
[40] C. De Lucia, P. Pazienza, and M. Bartlett, "Does good esg lead to better financial performances by firms? machine learning and logistic regression models of public enterprises in europe," Sustainability, vol. 12, no. 13 , p. $5317,202010.3390 /$ su 12135317

[41] T. Guo, N. Jamet, V. Betrix, L.-A. Piquet, E. Hauptmann, and R. A. Investments, "A deep learning framework for climate responsible investment." [Online]. Available: https://ram-ai.com/upload/tiny/Paper/A\%20Deep\%20Learning\% 20Framework\%20for\%20Climate\%20Responsible\%20Investment.pdf

[42] R. K. Pachauri, M. R. Allen, V. R. Barros, J. Broome, W. Cramer, R. Christ, J. A. Church, L. Clarke, Q. Dahe, P. Dasgupta et al., Climate change 2014: synthesis report. Contribution of Working Groups I, II and III to the fifth assessment report of the Intergovernmental Panel on Climate Change. Ipcc, 2014. [Online]. Available: https: //epic.awi.de/id/eprint/37530/1/IPCC_AR5_SYR_Final.pdf 